\title{
UNSTABLE DEGENERATIVE SPONDYLOLISTHESIS OF THE CERVICAL SPINE
}

\author{
A. DEBURGE, K. MAZDA. P. GUIGUI
}

From the Beaujon Hospital, Clichy: France

Unstable degenerative spondylolisthesis of the cervical spine is very rare. Slip usually occurs at the $\mathrm{C} 3$ on $\mathrm{C} 4$ or $\mathrm{C} 4$ on $\mathrm{C} 5$ levels, immediately above a stiff lower cervical spine. There are two clinical patterns: that with neurological involvement causing cervicobrachial pain or myelopathy and that with neck pain alone. The diagnosis can be made by flexion/extension radiography. All of our eight patients had localised fusion, three anterior and five posterior, and all had satisfactory results one to seven years after operation.

J Bone Joint Surg /Br/ 1995:77-B:122-5.

Received 12 January 1994: Accepted after revision 17 June 1994

Cervical spondylolisthesis does not often cause instability. We have retrospectively reviewed eight such patients treated by localised fusion, and discuss the pathogenesis and management of the condition.

\section{PATIENTS AND METHODS}

From 1976 to 1991 only eight patients with unstable degenerative spondylolisthesis of the cervical spine have required operation at our clinic (Table I). We have reviewed these three men and five women, who ranged in age from 65 to 82 years.

All eight patients had had symptoms for six months to two years before they were referred to us. Four had had severe neck pain with no neurological impairment, one had had severe neck pain and right brachialgia with no precise pattern of nerve-root involvement. Two had had signs of cord compression, one with intermittent changes only on neck flexion and one with permanent signs. The last patient, an 82-year-old man. had had slight neck pain at the onset, but was almost painfree when he was seen. None had a history of trauma.

Plain radiographs showed degenerative spondylolisthesis in all eight patients. The level of the slip was at $\mathrm{C} 3$ on $\mathrm{C} 4$

A. Deburge. MD. Professor of Orthopaedic Surgery

K. Mazda, MD. Orthopaedic Surgeon

P. Guigui. MD. Orthopaedic Surgeon

Department of Orthopaedic Surgery. Beaujon Hospital. 100 Boulevard du Général Leclerc. 92110 Clichy. France.

Correspondence should be sent to Professor A. Deburge.

(1)1995 British Editorial Society of Bone and Joint Surgery $0301-620 \times / 95 / 1912 \$ 2 .(0)$ in one patient. $\mathrm{C} 4$ on $\mathrm{C} 5$ in four and $\mathrm{C} 7$ on $\mathrm{T} 1$ in one. Two patients had slips at both $\mathrm{C} 3$ on $\mathrm{C} 4$ and $\mathrm{C} 4$ on $\mathrm{C} 5$. Dynamic radiography showed instability at the involved level in all patients; reduction on extension was complete in four and incomplete in four. Of the three patients with neurological impairment two had gas myelography and one had MRI. We also performed MRI on the 82-year-old man with slight symptoms.

All eight patients had surgical arthrodesis, with no attempt to reduce the slip by more than that obtained by extension of the neck. Three had anterior fusions with plate fixation, and the other five had posterior fusions using wires in one case and a plate in four. Only two patients had neural decompression; a $\mathrm{C} 4$ corporectomy was performed on an 80-year-old woman with chronic cord compression and incomplete reduction on dynamic radiography. and another patient had a limited laminectomy as well as posterior fusion. This patient had no signs or symptoms of cord impairment, but MRI had shown an impending cord compression.

There were no complications of any of the operations. other than one superficial wound infection which healed without further surgery.

\section{RESULTS}

The results were assessed by an independent observer after follow-up of from one to seven years. There was bone fusion and satisfactory function in all eight patients. Neck pain had been either cured or greatly improved. The three patients with brachialgia and cord compression including the two treated without neural decompression. had all lost their symptoms. The patient who was almost symptom-free before operation was unchanged after surgery.

\section{DISCUSSION}

In contrast to the lumbar spine. unstable degenerative spondylolisthesis is rarely seen at cervical level. but a few cases have been reported (Deburge 1984: Deburge and Benoist 1987; Bohlman and Bolesta 1993).

Two clinical patterns of degenerative instability of the cervical spine should be distinguished: one produces myelopathy and the other produces only pain. Cord compression causing myelopathy may be due to static compression from a partially fixed subluxation or to the so-called pincher' phenomenon by which instability produces a guillotine 
Table I. Details of eight patients having fusion for unstable cervical spondylolisthesis. All were cured of their pain and both patients with cord impairment had unlimited walking ability

\begin{tabular}{lllllll}
\hline Case & Sex & $\begin{array}{l}\text { Age } \\
(\mathbf{y r})\end{array}$ & Symptoms & Level of slip & Fusion & Laminectomy \\
\hline S & M & 65 & Neck pain & C3 on C4 & Anterior & No \\
2 & F & 70 & Neck pain & C3 on C4. C4 on C5 & Posterior & No \\
3 & M & 70 & Neck and arm pain & C3 on C4. C4 on C5 & Posterior & No \\
4 & F & 65 & Neck pain & C7 on T1 & Posterior & No \\
5 & F & 68 & Neck pain & C4 on C5 & Posterior & No \\
6 & F & 80 & Neck pain. cord impairment & C4 on C5 & Anterior & Yes \\
7 & F & 68 & Neck pain. cord impairment & C4 on C5 & Anterior & No \\
8 & M & 82 & Slight neck pain & C4 on C5 & Posterior & Yes \\
\hline
\end{tabular}

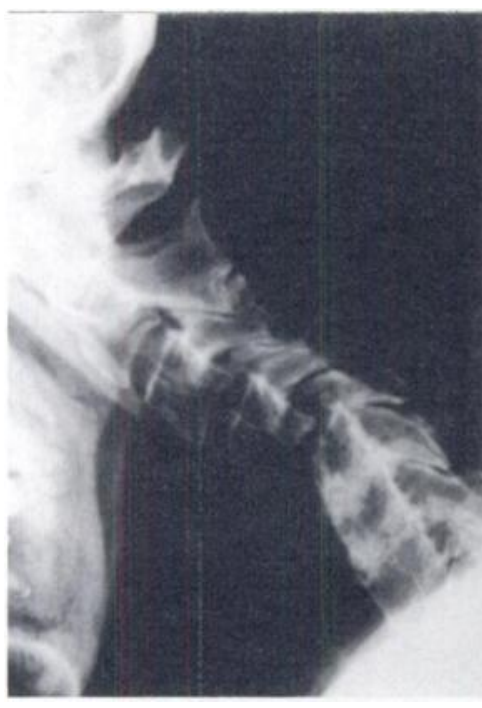

Fig. la

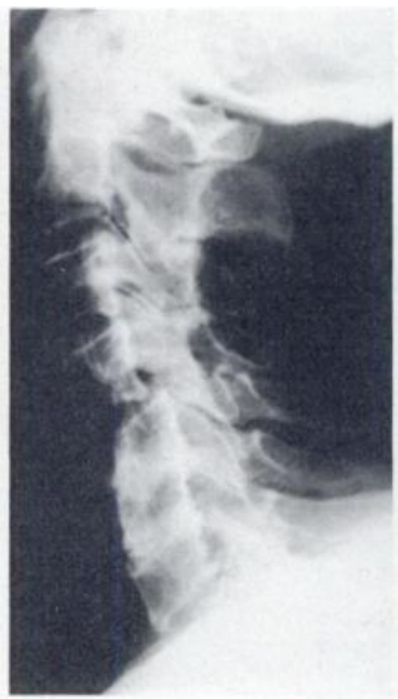

Fig. Ib

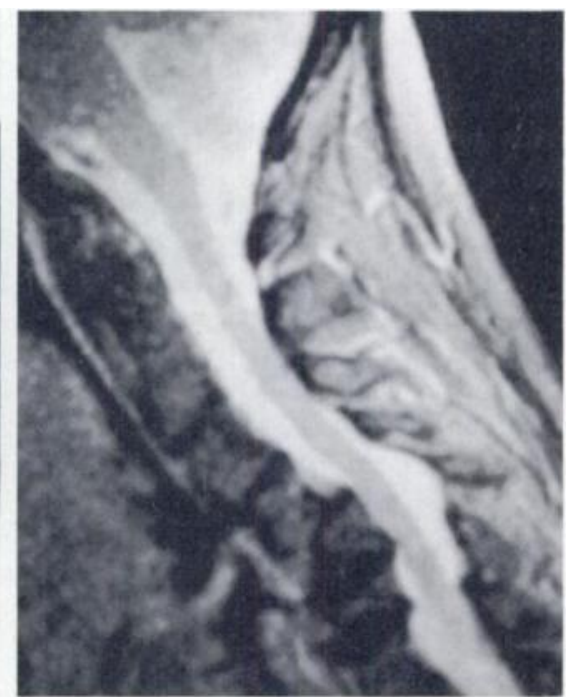

Fig. 1c

Figures $\mathrm{la}$ and $\mathrm{lb}$ - Radiographs of an 82-year-old man suffering from neck pain with no neurological signs. There is a slip at Ct on $\mathrm{C} 5$ above a spontaneous ankylosis. In the extension view reduction of the slip is incomplete. Figure Ic - T2-weighted MRI shows the threat of cord compression.

effect on the cord (White and Panjabi 1988). Our three patients with neurological signs of cord impairment demonstrate this pattern. The clinical pattern is characterised by permanent or recurrent neck pain. Unstable degenerative spondylolisthesis is much rarer than the presence of the stable slip and is more likely to cause neck pain.

Degenerative changes usually affect the whole cervical spine, but of our eight patients. all but one had instability at either $\mathrm{C} 3$ to $\mathrm{C} 4$ or $\mathrm{C} 4$ to $\mathrm{C} 5$, and in most of them the level below the unstable one was stiff (Fig. 1). During the time covered by this study, we saw no other patient with an unstable cervical spondylolisthesis. Since 1991, we have seen two other patients: both have chronic pain and surgery is planned but has been delayed. Stable degenerative spondylolisthesis with no hypermobility on dynamic radiography is less rare. We have seen a small number of such patients but neck pain was not severe and surgery was not offered in the absence of instability.

Hayashi et al (1987) compared the dynamic radiological characteristics of 100 normal subjects older than 60 years with those of younger subjects. Narrowing of the discs and osteophytosis were common in the older group at C5 to C6 and $\mathrm{C} 6$ to $\mathrm{C} 7$ levels, with a significant decrease in intervertebral mobility. This had resulted in a comparatively greater mobility at the higher $\mathrm{C} 3$ to $\mathrm{C} 4$ and $\mathrm{C} 4$ to $\mathrm{C} 5$ levels, where the disc space was well maintained. The conclusions are in keeping with our findings for a comparable age group. Another factor is that the lower and middle levels of the cervical spine show different patterns of movement (Penning 1978). At C3 to C4 and C4 to C5 there is some sliding of the superior over the inferior vertebrae, while there is little sliding at the $\mathrm{C} 5$ to $\mathrm{C} 6$ and $\mathrm{C} 6$ to $\mathrm{C} 7$ levels. 


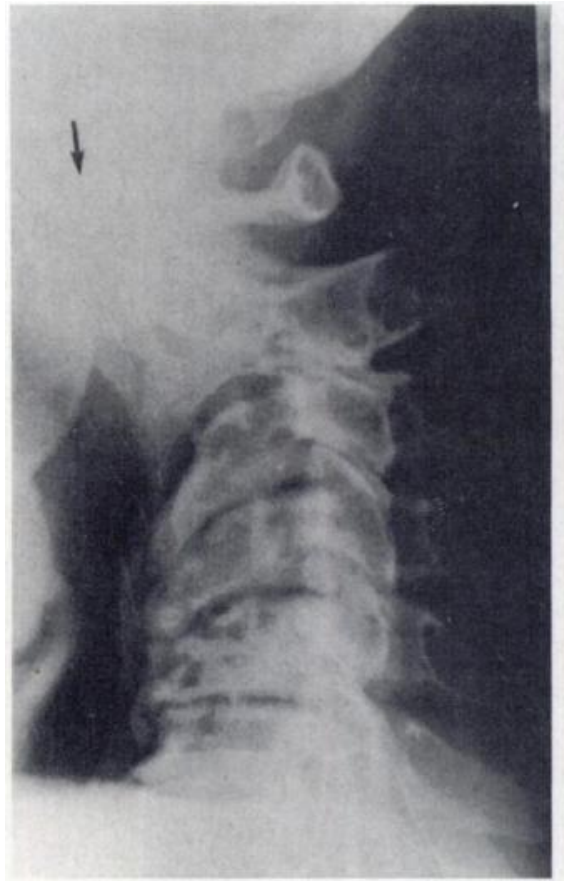

Fig. 2a

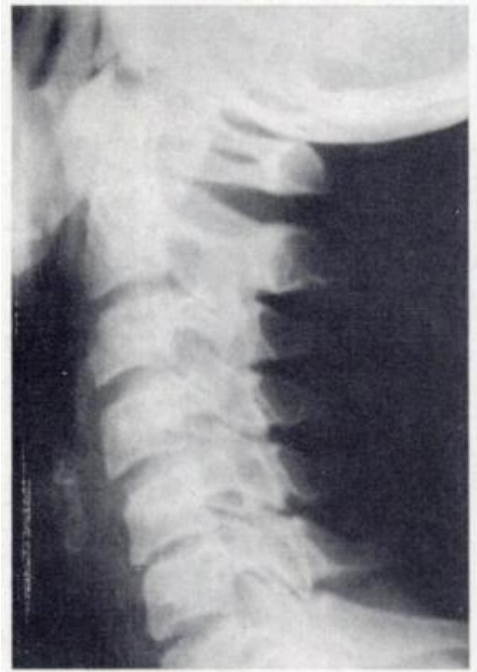

Fig. 3a

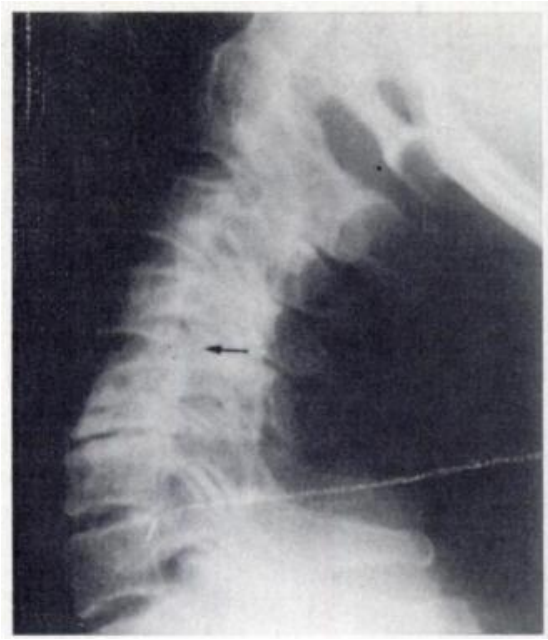

Fig. 3d
A. DEBURGE, K. MAZDA P GLIGLI

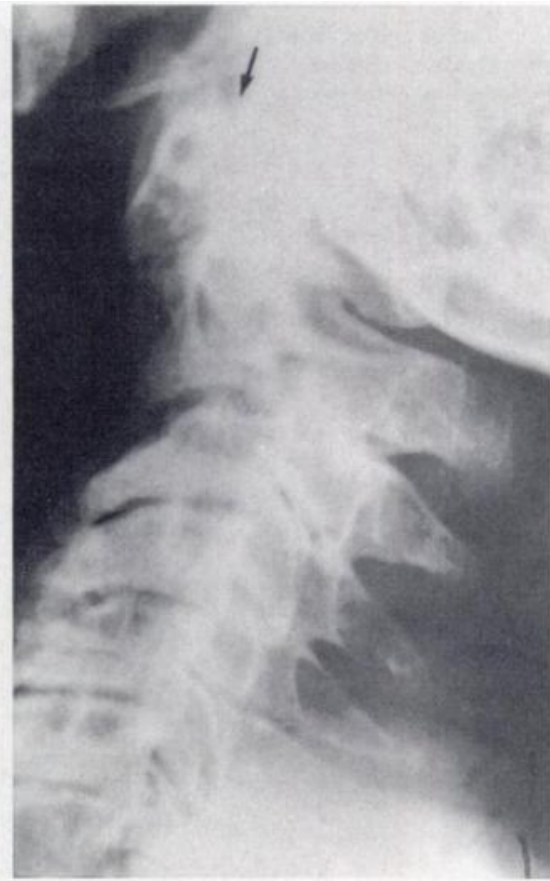

Fig. 2b

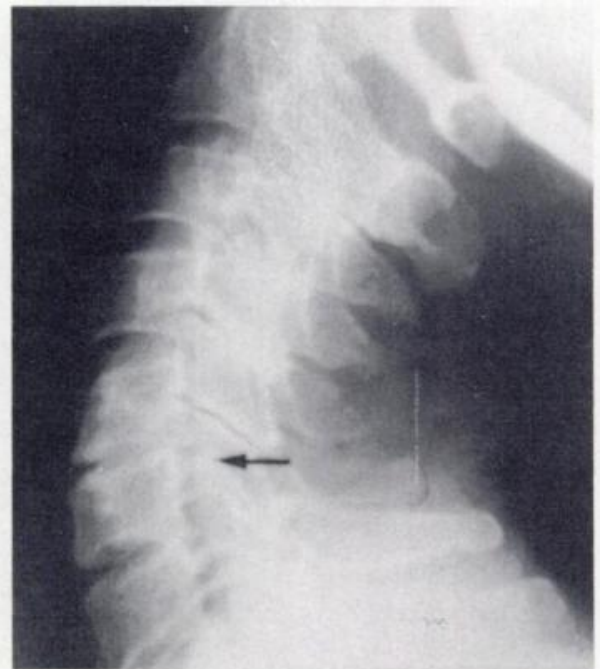

Fig. 3h

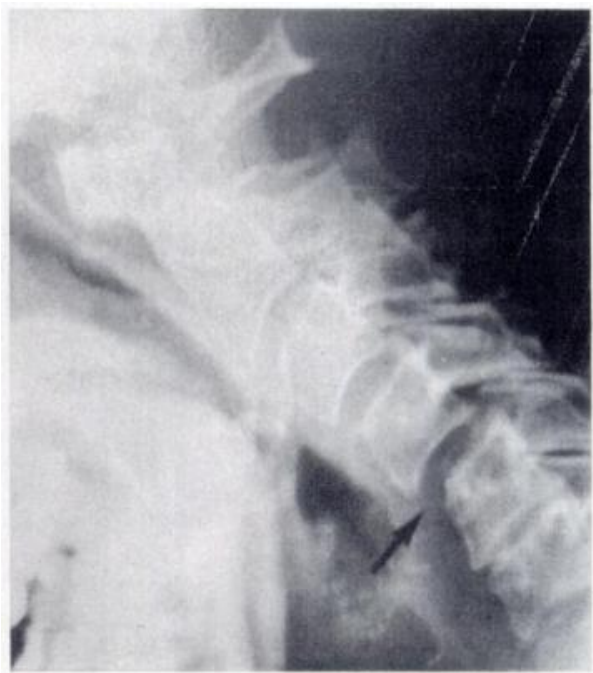

Fig. 3c

Radiographs of a 6.5-vear-old woman (not in the series reported here) with neck pain There is instability of $\mathrm{Cl}$ on $\mathrm{C}_{2}$, above a fixed slip. The lower cervical spine is completely rigid. 
The preferential location of degenerative instability in the middle cervical spine may be explained by the relative hypermobility and the different pattern of movement in association with the relaxation of surrounding ligament and degenerative changes in articular cartilage. If the whole lower cervical spine is rigid, then instability may occur at the upper levels. We have recently seen a 65 -year-old woman with intense neck pain and diffuse degenerative changes from $\mathrm{C} 2$ to $\mathrm{T} 1$. The dynamic radiographs showed no mobility at any of these levels, even at $\mathrm{C} 2$ to $\mathrm{C} 3$, where there was a fixed slip. There was instability, however, at $\mathrm{Cl}$ to C2: the space changed from $2 \mathrm{~mm}$ in extension to $5 \mathrm{~mm}$ in flexion (Fig. 2).

The evolution of such cervical instability is shown in the radiographs of a patient first seen by us in 1993 with an incompletely reducible forward slip at $\mathrm{C} 4$ on $\mathrm{C} 5$, and a mobile backward slip at C5 on C6 (Fig. 3). Previous radiographs have shown that degenerative changes started in the middle cervical spine in 1974, and by 1987 , both spondylolisthesis at $\mathrm{C} 4$ to $\mathrm{C} 5$ and retrospondylolisthesis at C5 to C6 were present but still mobile. Cervical instability seems to develop over a long period of time.

Arthrodesis seems to be the appropriate treatment for symptomatic instability. We recommend that the slip is not reduced any more than the reduction obtained on extension radiographs; our clinical results suggest that anatomical reduction is not mandatory. Our retrospective study showed equally good results from either an anterior or a posterior approach. When there is neurological impairment, decompression may be indicated, although our series included two patients with such impairment who recovered completely with stabilisation only.

We now perform routine flexion and extension radiography in every patient with symptomatic cervical spondylosis, because we believe that symptoms due to instability can be relieved by a limited fusion, without decompression.

The authors wish to thank Mr Stokes for reviewing the manuscript. No benefits in any form have been received or will be received from a commercial party related directly or indirectly to the subject of this article.

\section{REFERENCES}

Bohlman HH, Bolesta MJ. Degenerative spondylolisthesis of the cervial spine. Procs 60th annual meeting American Academy of Orthopaedic Surgeons, San Francisco. 1993:237.

Deburge A. Instability of the cervical spine due to arthrosis: an unusual form of degenerative spondylolisthesis. Rev Chir Orthop Reparatrice Appar Mot 1984:70:397-9.

Deburge A, Benoist M. Instability in cervical arthrosis. In: Kehr P. Weidner A. eds. Cenvical spine I. Wien. etc: Springer-Verlag. 1987: 38-40.

Hayashi H, Okada K, Hamada M, Tada K, Ueno R. Etiologic factors of myelopathy: a radiographic evaluation of the ageing changes in the cervical spine. Clin Orthop 1987:214:200-9.

Penning L. Normal movements of the cervical spine. AJR 1978:130:317-26

White AA, Panjabi MM. Biomechanical considerations in the surgical management of cervical spondylotic myelopathy. Spine 1988: 13:856-60. 